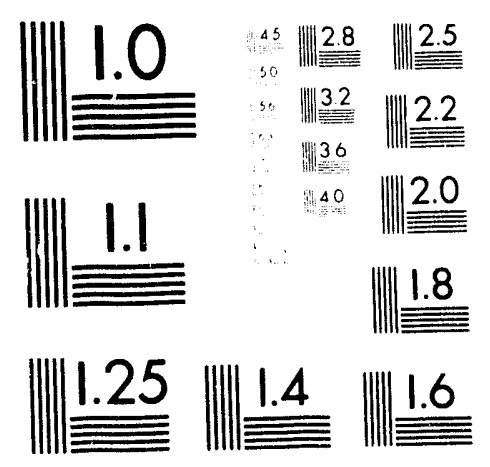



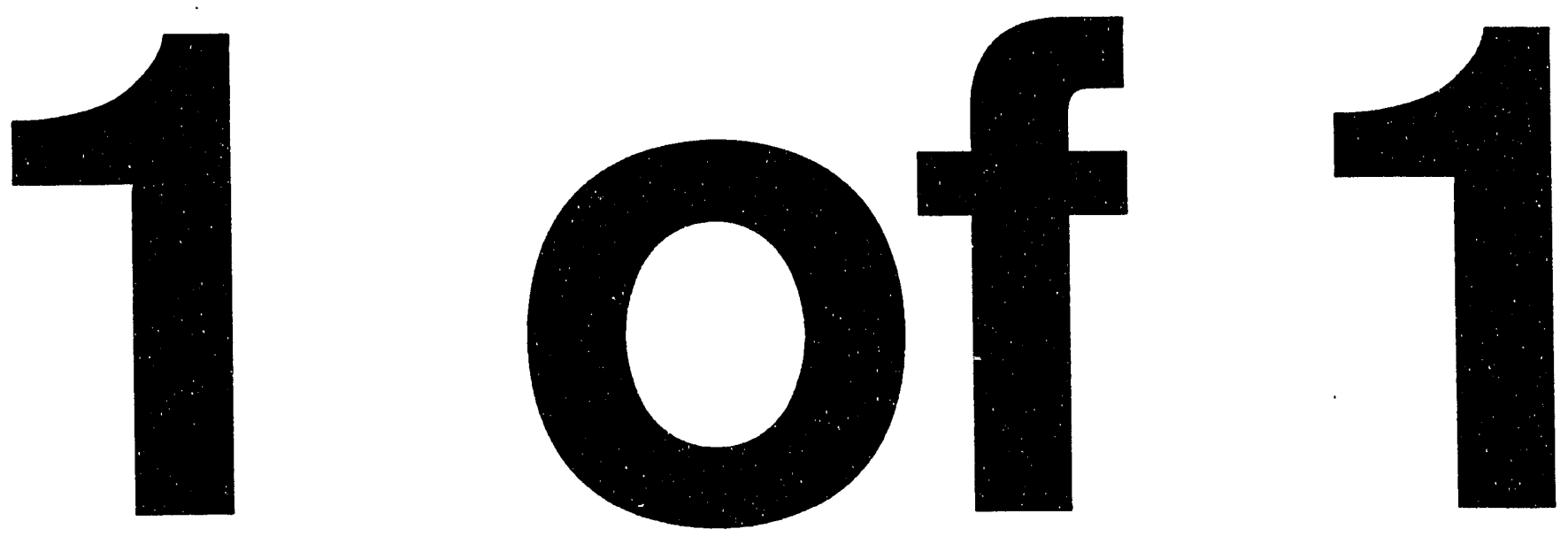
DOE/RL-91-40

Revision 0

UC-630

\section{Hanford Past-Practice Strategy}

K. M. Thompson

U.S. Department of Energy, Richland Operations Office

Date Published

November 1991

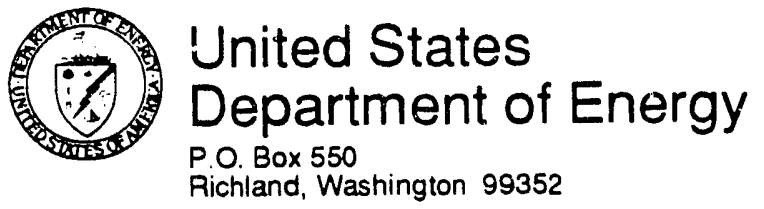


DOE/RL-91-40, Rev. 0

\section{CONTENTS}

INTRODUCTION . . . . . . . . . . . . . . . . . . . . . . . . . . 1

DEFINITIONS . . . . . . . . . . . . . . . . . . . . . . . . 3

ACRONYMS . . . . . . . . . . . . . . . . . . . . . . . . 6

OBJECTIVES . . . . . . . . . . . . . . . . . . . . . . . . 7

PROGRAMMATIC DECISIONS . . . . . . . . . . . . . . . . . . . . . 10

EXPEDITED RESPONSE ACTION DECISION . . . . . . . . . . . . . . 12

INTERIM REMEDIAL MEASURES DECISION . . . . . . . . . . . . . . . . . . . 13

LIMITED FIELD INVESTIGATION DECISION . . . . . . . . . . . . . . . 14

FINAL REMEDY SELECTION FOR THE OPERABLE UNIT . . . . . . . . . . . . . . . . 15

GENERAL DECISIONS ........................ . . . . 15

CHANGES TO AGREEMENT PRIORITIES AND MILESTONES . . . . . . . . . . . 18

NATIONAL ENVIRONMENTAL POLICY ACT (NEPA) COMPLIANCE $\quad . \quad$. . . . . . . 19

STRATEGY . . . . . . . . . . . . . . . . . . . . . . 20

DATA EVALUATION . . . . . . . . . . . . . . . . . . . 21

EXPEDITED RESPONSE ACTION PATH . . . . . . . . . . . . . . . . . . 24

INTERIM REMEDIAL MEASURES PATH . . . . . . . . . . . . . . . . 27

LIMITED FIELD INVESTIGATION PATH . . . . . . . . . . . . . . . . . 28

FINAL REMEDY SELECTION . . . . . . . . . . . . . . . . . . . . . 28

IMPLEMENTATION . . . . . . . . . . . . . . . . . . . . . . . . 31

REFERENCES . . . . . . . . . . . . . . . . . . . . . . . . . . . 31

FIGURE :

1 Hanford Past-Practice RI/FS Process . . . . . . . . . . . . . . 11

ATTACHMENT 1 - MEMORANDUM: DOE-RL/CCC I91-ERD-201

ATTACHMENT 2 - LETTER: DOE-RL/CCC I92/TPA-069 
DOE/RL-9l-40, Rev. 0

\section{INTRODUCTION}

In May 1989, the U.S. E../ironmental Protection Agency (EPA), the State of Washington Department of Ecology (Ecology) and the U.S. Department of Energy (DOE) entered into an Interagency Agreement to provide a legal and procedural framework for cleanup and regulatory compliance at numerous hazardous waste sites at the Hanford Site.

Four subareas of the Hanford Site (the 100, 200, 300, and 1100 Areas) have been included on the EPA's National Priorities List (NPL). Under the Hanford Federal Facility Agreement and Consent Order (Tri-Party Agreement), the more than 1,000 inactive waste disposal and unplanned release sites were originally grouped into 78 operable units ( 74 source operable units and 4 groundwater operable units, which underlie the source units). The contamination is in the form of solely hazardous waste, radioactive mixed waste, and other Comprehensive Environmental Response, Compensation and Liability Act (CERCLA) hazardous substances. Included within the Tri-Party Agreement are 55 Resource Conservation and Recovery Act (RCRA) treatment, storage, or disposal (TSD) facilities, which will be closed or permitted to operate in accordance with Washington Administrative Code (WAC) 173-303 (RCRA) regulations. Some of these TSD facilities are included in the operable units. The Tri-Party Agreement requires that the cleanup programs at Hanford integrate the requirements of the CERCLA program, the federal RCRA/Hazardous and Solid Waste Amendments of 1984 (HSWA) program, and the state's Dangerous Waste program. As such, the scope of the agreement includes all actions through CERCLA remedial actions and RCRA/HSWA corrective measures. At the same time, it integrates activities related to RCRA interim status compliance, RCRA permitting, and RCRA closure activities that apply to the TSD units.

While the EPA maintains authority for CERCLA, Ecology has received authorization from EPA to implement the state's Dangerous Waste program in lieu of the federal RCRA program. In addition, the state has received authorization to implement the EPA's Radioactive Mixed Waste program. The state does not yet have HSWA authority and that authority remains under EPA. Thus, as a result of the rather complex regulatory involvement coupled with the sheer size of the cleanup program, a major challenge of the Tri-Party Agreement is to coordinate, in a cost-effective and timely manner, the different requirements of CERCLA, RCRA corrective action, and RCRA TSD activities. In many cases, these activities occur at the same physical location.

The experience gained to date on developing the work plans and permit applications has shown the need for rethinking the strategy of RCRA/CERCLA integration beyond that specified in the Tri-Party Agreement to provide for greater uniformity in the applicability of requirements to the Hanford Site. The first four operable units to be investigated (1100-EM-1, 200-BP-1, $300-F F-1$ and $300-F F-5$ ) utilize the CERCLA RI/FS process and EPA as the lead regulatory agency. Due to complexity of the Hanford Site operable units, particularly with regard to characterizing existing mixed waste and hazardous waste contamination, and the need to obtain sufficient quantities of data necessary to provide a high degree of certainty in decision making, the schedules for investigations have become very long, ranging from $31 / 2$ to 7 years. For the same reasons, the costs of the RI/FS showed growth we 11 beyond initial expectations. Further, because there were no plans to provide 
for any cleanup actions to commence until the record of decision (ROD) was issued following the RI/FS, DOE and the regulatory agencies became concerned that too much time and too large a fraction of a limited budget would be spent before evidence of actual cleanup could be demonstrated. The lessons learned from work plan development also showed that there was a need to more closely integrate source and groundwater operable units such that the information gained from each of the investigations was in sync and available for input into the source and groundwater risk assessments conducted in parallel. Also, since a groundwater operable unit covers an area that encompasses several source operable units, many of which are scheduled for investigation much later in the program, there was a need for early identification of the specific sites within source operable units that are significant contributors to groundwater contamination. It was agreed that these significant contributor sites should be brought forward into the overall investigation and risk assessment for the groundwater aggregate area.

Through the lessons learned in work plan development, all parties to the Tri-Party Agreement recognized that all past-practice investigations must be managed and implemented under one characterization and remediation strategy regardless of the regulatory agency lead (as defined in the Tri-Party Agreement) and the applicable regulations (CERCL $\dot{A}$ or RCRA corrective action). In addition, there was a need to coordinate past-practice investigations with RCRA closure activities since some operable units contain RCRA TSD facilities. The high costs and long schedules associated with traditional past-practice investigations have given the parties a new perspective on the need to streamline the RI/FS and RFI/CMS processes. In addition, and perhaps most importantly, the parties have recognized that, since the goal of the program is cleanup, much more emphasis needs to be placed on initiating and completing waste site cleanups through interim measures. While investigations and studies are important in meeting long-range goals, there is now agreement by the parties that an appropriate and significant portion of the near-term funding resources can and should be dedicated to remedial work, where there is sufficient information from which to $\mathrm{plan}$ and implement interim remedial measures.

The parties have undertaken an ongoing dialogue over the past year to develop a new strategy for streamlining the past-practice corrective action process. This strategy provides new concepts for (1) accelerating decision making by maximizing the use of existing data consistent with data quality objectives and (2) undertaking expedited response actions and/or interim remedial measures as appropriate to either remove threats to human health and welfare and the environment or to reduce risk by reducing toxicity, mobility, or volume of contaminants. 
DOE/RL-91-40, Rev. 0

\section{DEFINITIONS}

Terminology used in this document is intended to be consistent with terminology specified in referenced statutes, regulations, proposed regulations and the Tri-Party Agreement. However, in order to fully describe the concepts of the strategy under development, some terms are used that may not exist in the referenced sources or may exist but are used in a different context in this document such that a specific cross-reference is needed to clarify the intended Tri-Party Agreement application. Terms that fall into either of these categories are defined below. If not 1 isted, the term will have the meaning given in the statute, regulation, or Tri-Party Agreement from which it is derived.

Aggregate area - for the purpose of this strategy, means a delineation of two or more waste sites, waste area groups, operable units, or any other basis for aggregation deemed appropriate by the parties to provide for more streami ined investigations, studies, or remedial actions. The intent of aggregation is to avoid duplication of investigations or studies by recognizing that many sites, waste area groups, or operable units may have such similar characteristics that it is more technically advantageous and cost effective to perform investigations or studies on the aggregate area basis rather than on an individual operable unit basis.

This term is also used in the Tri-Party Agreement Action Plan (see Section 7.1) to define the four subareas of the Hanford Site that are included on the NPL.

Baseline Risk Assessment - has the meaning as described in, "Guidance for Conducting Remedial Investigations and Feasibility Studies under CERCLA", EPA 540 G-89 004, Section 3.4.2. The Hanford baseline risk assessment methodology is being developed urider Milestone M-29 of the Tri-Party Agreement Action Plan.

Confirmation (of data), confirmatory (studies, sampling, investigations) means field investigations and/or laboratory analyses conducted for the purpose of verifying previous data to meet data quality objectives.

Data quality objectives (DQO) - means qualitative and quantitative statements that specify the type, amount, and quality of the data required to support Agency decisions during remedial response activities. DQO are determined based on the end uses of the data to be collected (see "Data Quality Objectives for Remedial Response Activities - Development Process," OSWER Directive 9355.0-07B, March 1987).

Emergency (response or action) - means a time-critical expedited response action (ERA) performed in response to a situation where the risk to human health or welfare or the environment is immediate aild the need for response is urgent.

Engineering evaluation/cost analysis (EE/CA) - means an analysis of removal alternatives for a site as defined in 40 CFR 300.415 (b)(4). 
Expedited feasibility study, abbreviated feasibility study, focused feasibility study - means a feasibility study conducted such that a limited number of alternatives are evaluated that are focused to the scope of the response action planned. Discussion and examples are given in the National Contingency Plan (NCP) preamble in 55 FR 8704.

Expedited response action (ERA) - means an onsite response action to abate a threat to human health or welfare or the environment. ERA are either removal actions under the DOE authority of the Atomic Energy Act, removal actions under CERCLA 40 CFR 300.415, or interim measures (as deemed appropriate) under RCRA proposed 40 CFR 264.540 (see Interim Measure(s) below). ERA include responses to both time-critical and nontime-critical situations (see definitions below).

Expedited treatment study - means advancing treatment or treatability studies of promising or most likely technologies to occur early in the remedial investigation or aggregate area management study (AAMS). Discussion of this concept is given in EPA's management systems review (MSR) (Ref 1 ).

Focused remedial investigation - means focusing the remedial investigation to collect only additional data needed to develop and evaluate alternatives and to support design (see 53 FR 51423, 55 FR 8704).

Interim remedial measure (IRM) - means an onsite response conducted pursuant to CERCLA 40 CFR 300.430 involving interim remedial actions that are conducted at a CERCLA past-practice operable unit at any time prior to initiation of final remedial action. IRM can include RCRA interim measures as deemed appropriate by the parties (see Interim Measure(s) below). A discussion of interim response actions is given in the TriParty Agreement, Article XIII, paragraph 38, and the Action Plan, Section 7.2.4.

Interim measure(s) - A RCRA regulatory term that represents a class of interim actions that are conducted at a RCRA past-practice operable unit at any time prior to initiation of the final corrective measure in accordance with a permit modification or $3008(\mathrm{~h})$ order. A RCRA interim measure, in the context of this strategy, can be either an ERA or an IRM as deemed appropriate by the parties. The term is discussed in the Tri-Party Agreement, Article XIII, paragraph 39, and in the Action Plan, Section 7.2.4. Regulations for interim measures are defined in proposed RCRA Subpart S regulations 40 CFR 264.540 (55 FR 30880). Interim measures may be appropriate in both time-critical and non-time-critical situations or as interim remedial measures. Corrective actions may also be initiated under $3008(h)$ authority.

Lead agency - means DOE as defined in 40 CFR 300.5 (55 FR 8816).

Lead regulatory agency - means that regulatory agency, EPA or Ecology, as defined in the Tri-Party Agreement, Article V, paragraph $21(R)$.

Limited field investigation - means the collection of limited additional site data that are sufficient to support a decision on concucting ERA or IRM. 
Non-time-critical (response or action) - means an expedited response action (ERA) needed to abate a threat to human health or welfare or the environment where sufficient time exists for formal planning prior to initiation of response. A non-time-critical ERA may also address a situation encompassing levels of contamination that do not pose an immediate danger or threat to human health or welfare or the environment, but which might justify a response action by the need to control the spread of contamination, to abate a threat, or provide for a greater overall cost effectiveness by more timely response. The preamble to the proposed NCP in 53 FR 51409 describes non-time-critical removals as those where, based on the site evaluation, the lead agency determines that a removal action is appropriate and that there is a period of more than 6 months available before onsite response activities must begin. (See 40 CFR $300.415(\mathrm{~m})$.) Non-time-critical ERA include CERCLA non-time-critical removals and certain RCRA interim measures as deemed appropriate by the parties.

Qualitative risk assessment - means a judgement not based solely on quantification, agreed to by the parties, based on available site data regarding the threat posed by site contamination.

Removal, removal action, removal authority - means action described and authority implemented in 40 CFR 300.415.

Remedy, remedial action - is defined in Section 101(24) of CERCLA and implemented in 40 CFR 300.430 .

Time-critical (response) - means expedited response action (ERA) performed under CERCLA or RCRA authority, which are needed to abate a threat to human health or welfare or the environment where long deliberation prior to initiation of onsite activities is neither feasible nor desirable (see FR 55 8695). Those actions include CERCLA time-critical removal actions and certain RCRA interim measures as deemed appropriate by the parties. The preamble to the proposed NCP in 53 FR 51409 defines timecritical removals as those where, based on the site evaluation, the lead agency determines that a removal action is appropriate and that there is a period of less than 6 months available before response activities must begin onsite. (See 40 CFR $300.415(\mathrm{~m})$.)

Validation (of data), validated data - means a systematic review conducted to confirm the degree of truth in an analytical measurement. The process includes the review of all pertinent sample analysis and quality assurance/quality control $(Q A / Q C)$ data compared to recognized standards or criteria. The review is conducted to ensure that data are adequate for their intended use(s). (See "A Proposed Data Quality Strategy for Hanford Site Characterization," WHC-SD-EN-AP-023, Rev. 0, January 19, 1990.)

Verification (of data), verified data - means to determine or test the truth or accuracy by comparison or reference. (See "A Proposed Data Quality Strategy for Hanford Site Characterization, "WHC-SD-EN-AP-023, Rev. 0, January 19, 1990.) 
DOE/RL-91-40, Rev. 0

\section{ACRONYMS}

AAMS

AAMSR

ARAR

CERCLA

DOE

DOE-RL

DQO

Ecology

$E E / C A$

EPA

ERA

HSWA

IRM

LFI

MSR

NCP

NEPA

NPL

OSWER

$\mathrm{PA} / \mathrm{SI}$

$Q A / Q C$

RCRA

RFA

RF I /CMS

$\mathrm{RI} / \mathrm{FS}$

ROD

TPA

TSD aggregate area management study

aggregate area management study report

applicable or relevant and appropriate requirements

Comprehensive Environmental Response, Compensation and Liability Act

U.S. Department of Energy

U.S. Department of Energy, Richland Operations Office data quality objectives

State of Washington Department of Ecology

engineering evaluation/cost analysis

U.S. Environmental Protection Agency

expedited response action

Hazardous and Solid Waste Amendments of 1984

interim remedial measures

limited field investigation

management systems review

National Contingency Plan

National Environmental Policy Act

National Priority List

Office of Solid Waste and Emergency Response

preliminary assessment/site investigation

quality assurance/quality control

Resource Conservation and Recovery Act

RCRA facility assessment

RCRA facility investigation/corrective measures study remedial investigation/feasibility study

record of decision

Tri-Party Agreement or the Hanford Federal Facility Agreement and Consent Order

treatment, storage, or disposal 


\section{OBJECTIVES}

A primary objective of this strategy is to develop a uniform, stream1 ined process to meet statutory requirements and integrate CERCLA RI/FS and RCRA past-practice RFI/CMS guidance and ensure the protection of human health and welfare and the environment at the Hanford Site through effective cleanup actions (effective both in terms of protection and cost). DOE's responsibilities and authorities under the Atomic Energy Act of 1954 (as amended) are not included in the considerations of this strategy. The strategy must satisfy the Tri-Party Agreement and, in turn, RCRA and CERCLA requirements. This process will be used in both EPA- and Ecology-lead past-practice units.

The objective of this document is to describe concepts and framework for the RI/FS process, in a manner that has a bias-for-action through optimizing the use of interim remedial actions, culminating with decisions on final remedies on the operable unit and aggregate area scale. The overall process leading to final ROD is described in general terms; however, mor a details are given regarding the initial stages of Hanford cleanup that focus on reaching early decisions to initiate and complete cleanup projects. These early decisions will maximize the use of existing data coupled with focused short time-frame investigations where necessary. As more becomes known about the contamination problems and associated risks through interim actions and through the early, priority-based investigations and studies, the details of the longer-term investigations and studies will be better defined. The parties recognize that the details of most longer-term programs cannot be effectively specified when operable unit work plans are initially written. To define such specifics requires more information, which is expected to be forthcoming as results of the near-term work become available. The parties intend that such definition be provided by mutual consultation and incorporated as future work plan addendums, specific agreed-to statements of work, etc., which will be reflected in Appendix $D$ of the Tri-Party Agreement Action Plan.

The strategy recognizes that the RI/FS process is a continuum of activities whereby the effort is defined based on knowledge gained as work progresses. Thus, vork plans are intended to: (1) describe in detail what is known about the operable unit; (2) describe in detail the agreed-on focused and priority-based investigations, agreed to when the work plan is submitted for approval; and (3) describe in general terms the framework and process to be followed for the overall RI/FS (RFI/CMS) process.

The parties intend that this strategy be consistent with the requirements of the NCP and RCRA. The strategy defines the Hanford RI/FS (RFI/CMS) process. While the strategy is intended to streamline investigations and documentation, and to promote the use of interim actions to accelerate cleanup, the elements of the investigations and interim actions are in aggregate, intended to meet all of the objectives of the RI/FS and RFI/CMS processes.

The initial stages of Hanford cleanup will optimize the use of interim cleanup actions when justified and practicable. Existing data will be evaluated as the initial basis for decision making. If the data are found to be insufficient, additional essential data will be collected to support the IRM in a limited field investigation (LFI). Only data needed to formulate a 
conceptual model (source to pathway to receptor) and qualitative risk assessment would be obtained. The data quality objectives of the LFI will be established based on the use of the data in deciding on IRM. The data might not need to be of the same quality needed to support final ROD. The IRM itself would yield valuable quality information for supporting the final ROD. As IRM are completed, the later stages of the program would involve more thorough assessment of cumulative risks and environmental effects. In short, the objective would be to achieve real cleanup, where it is obviously necessary to bring health and environmental risk into acceptable levels in the shortest possible time, in a cost-effective manner. This would require that the initial focus of the IRM is on the most obvious problems and on the most achievable and cost-effective solutions.

As the cleanup program proceeds through IRM in the initial stages of cleanup, the strategy envisions that opportunities for effective IRM may diminish and the need for more comprehensive investigations leading to final remedy selection will then command an increasing shift of resources to complete characterization for cumulative risk assessments and final remedy selection.

The strategy must provide for ERA and IRM that are consistent with both regulatory requirement's and the Tri-Party Agreement Action Plan (Sections 7.2.3 and 7.2.4). ERA would meet the requirements of removal actions and IRM would meet the requirements of interim remedial actions, as provided in the EPA's NCP (40 CFR 300). Interim measures as provided in the proposed amendments to 40 CFR Parts 264-271 (55 FR 30798) could be performed either as ERA or IRM as deemed appropriate by the parties. This strategy will be revised to incorporate appropriate RCRA corrective action provisions upon adoption and regulatory review of the final rule.

The NCP provides further clarification of EPA's policy for expediting remedial actions:

"Remedial actions are to be implemented as soon as site data and information make it possible to do so" (40 CFR 300.430(a)(1));

"Sites should generally be remediated in operable units when early actions are necessary or appropriate to achieve risk reduction quickly, when phased analysis and response is necessary or appropriate given the size or complexity of the site, or to expedite the completion of total site cleanup." 40 CFR $430(a)(1)(i i)(A)$, and;

"Site-specific data needs, the evaluation of alternatives, and the documentation of the selected remedy should reflect the scope and complexity of the site problems being addressed." (40 CFR $300.430(a)(1)(i i)(C)) . "$

Investigations for RCRA TSD closures conducted within past-practice operable units will be fully integrated into past-practice aggregate area management studies, work plans, and the investigation and abatement process. These RCRA TSD closure investigations would comply with the substantive applicable requirements of RCRA. Section 6 of the Tri-Party Agreement Action Plan further describes implementation of RCRA at the Hanford Site. At the initiation of the first of either the RCRA TSD closure plan, or the pastpractice aggregate area management study or work plan, the involved parties 
(which would include DOE and either one or both of the regulatory agencies due to Tri-Party Agreement lead assignments) would meet to coordinate the schedules of the investigations or abatement activities and adjust milestones accordingly. The goal is to gain optimal efficiencies in site investigations by coordinating the field activities, while maintaining a schedule of investigations and abatement measures that assures protection of human health and welfare and the environment, documented in a compliance schedule of the Tri-Party Agreement.

The strategy must make more effective use of a process similar to the standard "scoping study" to gather and analyze existing data to allow a more limited and focused remedial investigation process. In this manner, the existing database would become the basis for decisions, where sufficient data and data quality exist. This premise of focused investigations is articulated in EPA's guidance to its remedial project managers (Ref 3 ):

"The objective of the scoping process is to develop a conceptual understanding of a site, based on existing information so that a sufficiently detailed work plan for conducting the necessary investigative and analytical tasks can be prepared."

"Experience has shown that despite how much money and time is spent on an RI/FS, some degree of uncertainty concerning the nature and extent of contamination and/or the expected performance of a remedial technology will remain. You should keep in mind that the objective of the RI/FS is not to remove all uncertainty, but to gather information sufficient to support an informed risk management decision regarding what remedy appears to be most appropriate given what is known about the site."

In cases where existing data are sufficient, it is appropriate to make the FS process much more efficient by initiating formal evaluations of remedial technologies during "scoping" and, by mutual consent of the three parties, reducing the number of alternatives evaluated. Further efficiencies can be realized in these cases if treatability studies are initiated early in the program. The number of alternative treatment technologies that would be evaluated in both the early case, as provided in this strategy, and in the detailed analysis of alternatives portion of the FS in the normal pastpractice process, could be limited because: the existence of few known effective and technically feasible remedial technologies available to address the particular site problems; recent abatement experience at similar sites; or applicability of particular applicable or relevant and appropriate requirements (ARAR) that might constrain the number of alternatives capable of meeting ARAR as required by the NCP. Also, for certain types of sites (e.g., large nonhazardous waste landfills), the number of treatment or containment alternatives evaluated might be reduced or alternatives eliminated if consistent with the EPA's expectation for remediating that particular type of site (NCP preamble 55 FR 8702-8703; NCP regulatory language, 40 CFR $300.430(a)(1)(i i i))$.

Finally, the strategy must identify critical programmatic decisions and the timing of those decisions. Such decisions are important to the implementation of the strategy. All of these objectives are in keeping with the ultimate goal of performing cleanup at the earliest possible date in the most effective manner that is technically sound. This is compatible with the 
stated goals of the EPA streamlining efforts as shown in the NCP and other documents.

An important objective of the strategy will be for the parties to work together in identifying the best mix of ERA, IRM, and investigations to optimize the use of available resources. The goal of such optimization is to focus on real cleanup while still maintaining a technically sound and costeffective program of investigations that meets the intent of the Tri-Party Agreement.

\section{PROGRAMMATIC DECISIONS}

The recognition of several programmatic issues is critical to the development of the process for operable unit integration and streamining of the Hanford past-practice strategy. Agreement on these issues by the parties is also essential to the integration of investigation and remediation work addressing both past-practice and TSD facilities. It is not necessary that all programmatic decisions be made before start of work. However, as each element of the strategy is implemented, progressively more programmatic issues must be resolved before the process could continue. Each of the decisions discussed below has an impact on the level of effort that must be expended in reaching the ultinate cleanup goals.

The strategy presented in this document proposes three paths for decision making.
1. Expedited Response Action (ERA) Path
2. Interim Remedial Measure (IRM) Paich
3. Limited Field Investigation (LFI) Path.

The fina? remedy selection process for the operable unit will incorporate these three paths, and will integrate sites not addressed in the three paths. This constitutes the Hanford RI/FS (RFI/CMS) process (see Figure 1). Decision criteria and objectives are discussed below.

Also included in this section is a discussion of general programmatic decisions that affect all paths, a discussion of changes to the Tri-Party Agreement and Milestones required to accomplish the objectives of the new strategy, and a discussion of NEPA compliance. 
DOE/RL-91-40, Rev. 0

Figure 1. Hanford Past-Practice RI/FS Process.

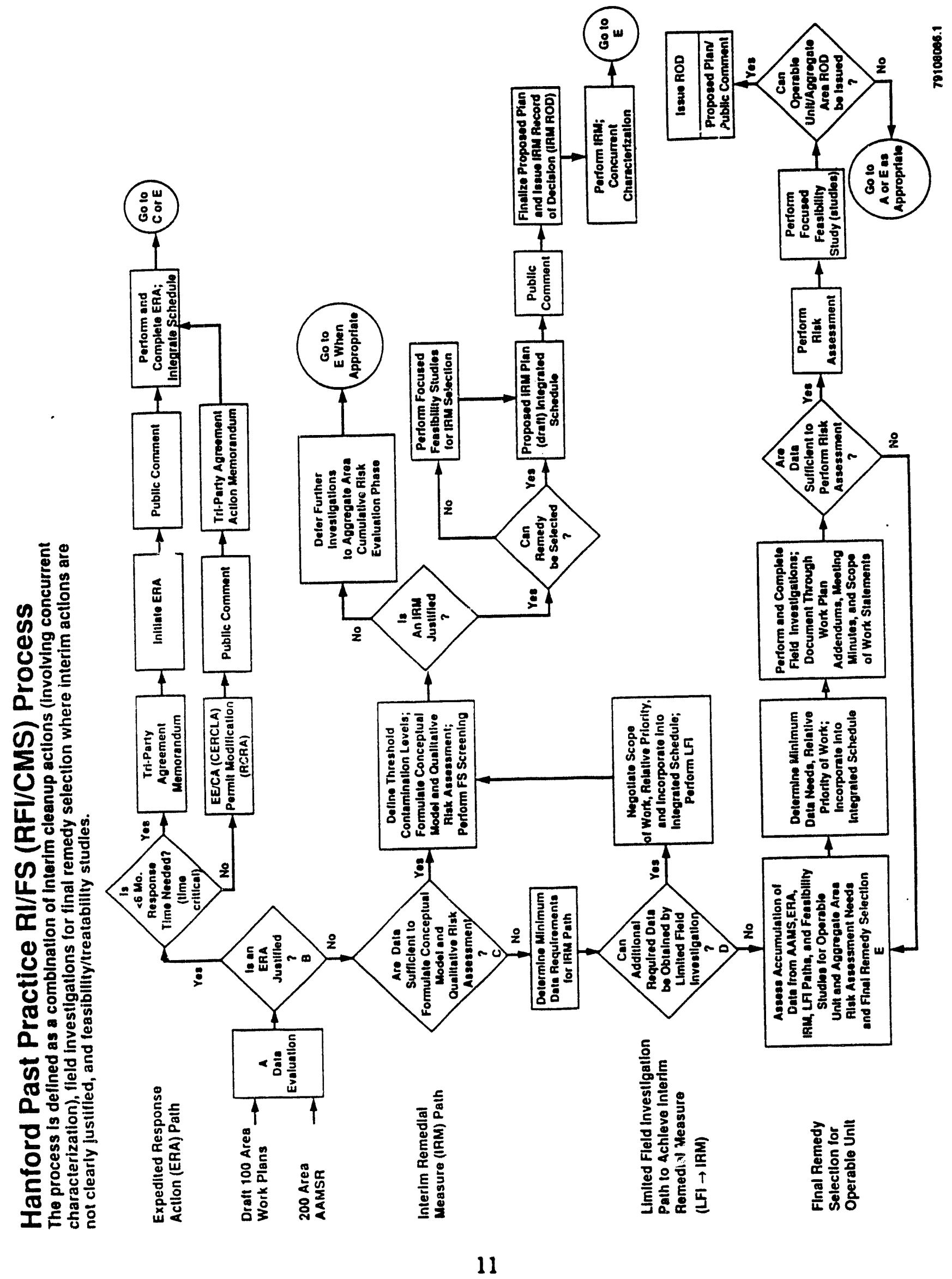




\section{EXPEDITED RESPONSE ACTION DECISION}

Conditions that might trigger an abatement as an expedited response action generally are the determination of, or suspected, existing, or future unacceptable health or environmental risk, and a short time-frame available to mitigate the problem. Conditions include, but are not limited to:

(A) Actual or potential exposure to nearby human populations, biota, or the food chain from hazardous substances and radioactive or mixed waste contaminants.

(B) Actua? or potential contamination of drinking water supplies or sensitive ecosystems.

(C) Threats of release of hazardous substances and radioactive or mixed waste contaminants.

(D) High levels of hazardous substances and radioactive or mixed waste contaminants in soils that pose or may pose a threat to human health or the environment, or have the potential for migration.

(E) Weather conditions that may increase potential for release or migration of hazardous substances and radioactive or mixed waste contaminants.

(F) The availability of other appropriate federal or state response mechanisms to respond to the release.

(G) Time required to develop and implement a final remedy.

(H) Further degradation of the medium which may occur if a response action is not expeditiously initiated.

(I) Risks of fire or explosion or potential for exposure as a result of an accident or failure of a container or handling system.

(J) Other situations or factors that may pose threats to human health or welfare or the environment.

These situations combine those provided for in 40 CFR 300.415 (b) (2) for removal actions under CERCLA and proposed 40 CFR 264.540(d) under RCRA for interim measures. Considerations in evaluating releases for determination of ERA would follow guidance provided in OSWER Directive 9902.4.

The process to select an ERA at Hanford is described in the Westinghouse Hanford document, Site Selection Process For Expedited Response Actions At The Hanford Site, WHC-MR-0290. Data and analyses from the resulting report would be assessed by Unit Managers, who would make a joint recommendation to the three project managers for decision. The recommendation need not be unanimous, and dissenting opinions would be included. If unanimity among the project managers was not reached, the mechanism for resolution to initiate an ERA or the schedule to perform the ERA would be the Tri-Party Agreement dispute resolution process. Nothing in this strategy should be construed as a waiver of Ecology or EPA authority to require an ERA as provided by RCRA, HSWA, CERCLA, or Section 7.2.4 of the Tri-Party Agreement Action Plan. 
The U.S. Department of Energy, Richland Operations Office (DOE-RL) would function as the "Lead Agency" as provided in the NCP, within the constraints of the Tri-Party Agreement. Ecology or EPA would function as the "Lead Regulatory Agency" depending on the designation of the operable unit as a RCRA Regulatory Agency" depending on the desictice unit in the Tri-Party Agreement.
past-practice unit or a CERCLA past-practice
If the operable unit has not been designated, EPA and Ecology would jointly choose an authority to address the expedited response action. The lead regulatory agency, in consultation with the support regulatory agency, would specify a submittal date for DOE's proposed abatement method and would approve the proposal.

Iime-Critical ERA - Emergency conditions posing a threat could trigger an immediate abatement effort. Such abatement efforts would be conducted as removal actions under CERCLA Sections 104 or 106 authority in accordance with 40 CFR 300.415 , as an action under RCRA Section 7003 or Section $3008(\mathrm{~h})$ authority. An ERA may under RCRA Section 7003 or section 3008 in a compliance with 40 CFR
be conducted as a RCRA interim measure in complions in this
264.540 , after the regulation is promulgated. Actions in
category are considered as time-critical situations, such as category are considered as time-critical situations, such as must be initiated within 6 months to abate the threat.
maction
mathent a

Non-Time-Critical ERA - An ERA that requires more extensive planning prior to implementation might be accomplished as either a CERCLA removal action or a RCRA interim measure as deemed appropriate by the parties. These actions meet the definition of non-time-critical and would be performed in a manner consistent with the appropriate requirements of 40 CFR 300.415 of the NCP. Non-time-critical actions may also be performed consistent with RCRA 40 CFR 264.540 Subpart S, after the regulation is promulgated. In such situations, a planning period of at least 6 months would exist before onsite activities must be initiated.

These decisions could also have an effect on the ability to meet milestones, in which case appropriate provisions of the Tri-Party Agreement would be followed to seek relief. However, that impact would be lessened by the ability to proceed with caution and planning.

Following successful completion of the ERA, an assessment of further action prior to the ROD would be made in consideration of other priorities.

\section{INTERIM REMEDIAL MEASURES DECISION}

It is not always necessary to extensively characterize a site before cleanup decisions can be made. Further, the NCP does not require an RI/FS prior to performing cleanup actions. The RI/FS is only a means to an end. Proposed Subpart S regulations provide regulatory agency discretion in the requirements for completing an RFI/CMS site characterization study prior to taking corrective action. The fundamental requirement is only that sufficient information be known from which a defensible decision (the ROD or permit modification) can be made. Further, both CERCLA and RCRA regulations encourage the execution of interim remedial measures as a positive means of cleanup at the earliest possible time. For many sites, sufficient data exist 
at an early stage in the investigation to make decisions on conducting IRM. Either a qualitative risk assessment or ARAR trigger would be required for initiating an IRM. The remedy might be obvious or, at most, a focused feasibility study might be needed to select a remedy. While the IRM decision accepts a larger bound of uncertainty in the supporting data, the conduct of the IRM will in itself produce a wealth of data to refine the conceptual model, quantify risk, and reduce uncertainty such that the final remedial decision might be made without resorting to any additional investigative measures. However, if at the end of the IRM process, there remains sufficient uncertainty regarding the final remedy, the process would then proceed to final remedy selection for the operable unit.

The DOE accepts the potential that the site(s) may need to be further remediated at some future date as a result of performing either ERA or IRM prior to full site characterization. During the corrective action process, unpredicted conditions may be found that may require additional measures to be undertaken. Corrective actions should be planned and conducted such that coincident confirmatory site and compliance characterization is accomplished. Further, the use of the observation approach (Ref 2 ) in cleanup actions would provide the flexibility necessary to adapt to the actual site conditions during renedial actions.

\section{LIMITED FIELD INVESTIGATION DECISION}

The concept of the limited field investigation provides a streamlined process by which site data, the minimum needed for IRM or other decisions, can be obtained in a less formal manner. The LFI is part of the RI. The LFI concept allows the parties more flexibility and opportunity for timely response. A key distinction between an LFI and an RI is that the RI is intended to be sufficiently comprehensive to support final ROD, whereas the LFI may or may not serve that purpose, depending on the scope of the LFI and the nature of its results. Several LFI and/or additional RI/FS investigations may be required to provide sufficient information for cumulative risk assessments and final remedy selection, depending on the scope and complexity of the operable unit or aggregate area. However, regardless of the scope of the LFI, it is intended that it be a part of the RI process not a substitute for it.

The LFI process would be described in the operable unit work plan, prepared by DOE as the lead agency, as the first step. During development of the operable unit work plan, the scope of this work and corresponding schedule would be the subject of discussion and negotiation among the parties at meetings of unit and/or project managers. Progress of the LFI would be reviewed by the parties at periodic meetings. Documentation of results would be transmitted in letters, meeting minutes, or topical reports. The data resulting from an LFI would then feed back through the decision process to assess which path to follow from this point, i.e., ERA, IRM, final remedy selection for the operable unit, or perhaps even through additional LFI. In addition to limited field investigations, the LFI process could include FS screening, if needed to select remedies for conducting ERA or IRM. 


\section{FINAL REMEDY SELECTION FOR THE OPERABLE UNIT}

The near-term strategy provides for ERA, IRM, and LFI for individual sites, site groups, or groundwater plumes. While these elements may be effective in mitigating specific contamination problems through the interim actions, the process of final remedy selection must be completed for the operable uni: or aggregate area to reach closure. The operable unit or aggregate area consists of numerous waste sites or groundwater plumes. As the program matures for the operable unit or aggregate area, a number of LFI, ERA, and/or IRM may have been conducted in specific areas. It is also possible that, based on the initial data evaluation, some investigations and/or cleanup actions may have been deferred to the final remedy selection phase for the operable unit. The aggregation of information obtained from the LFI and interim actions may be sufficient to perform the cumulative risk assessment and to define the final remedy for the operable unit or aggregate area. If data are not sufficient, additional investigations and studies will be performed to the extent necessary to support final remedy selection. Some investigations supporting final remedy selection on the operable unit/ aggregate area/NPL site scale may require a long-term effort, or it may be obvious that the collection of possible interim cleanup actions cannot provide the data necessary to address a required data need. These studies should be identified as soon as possible and initiated through the integrated schedule as the overall cleanup priorities dictate, with agreement by the Tri-Party Agreement participants. As with previous stages, such investigations and studies would be performed within the framework and process defined for RI/FS (RFI/CMS) programs, and would be tailored to meet the identified needs with the objective of reaching defensible decisions in a timely and cost-effective manner.

\section{GENERAL DECISIONS}

The following decisions affect the manner in which data evaluations, ERA, IRM, LFI, and RI/FS activities leading toward records of decisions are conducted, analyzed, and implemented.

Land Use - Past-practice cleanup actions are to be compatible with projected future land uses. An external-to-DOE (and the TPA) working group has been established to assist in the identification of alternatives.

Land use does not directly impact ERA or IRM, provided that these actions do not preclude and are compatible with reasonable land use options. Cleanup standards are established by the regulatory agencies under federal and state statutes, and their implementing regulations. However, these promulgated criteria, as allowed by applicable statutes and regulations, could be modified based on reasonable proposed 1 and uses. For example, groundwater standards could differ pursuant to WAC $173-340-720$.

Protective standards for interim and final cleanup actions will be based on case-by-case determinations. Cleanup requirements will result from selection of remedial alternatives, based on foreseeable uses of the 1 and. The issue of appropriate land use scenarios to be evaluated in qualitative and quantitative risk assessments will be addressed in the risk assessment methodology document, which will be prepared and 
issued under Milestone M-29 of the Tri-Party Agreement Action Plan; application of a particular scenario to guide cleanup decisions will be on a case-by-case basis (see Changes to Agreement and Milestones).

Point of Compliance - Point of compliance determinations must be made consistent with federal and state 1 aw and regulations. This issue is addressed in proposed 40 CFR 264.525(e) at 55 FR 30878, in 40 CFR 264.94(a), and in WAC 173-200, 173-340, and 173-303-645. The decision on point of compliance could impact investigation activities, remedial alternative determinations, and long-term monitoring requirements. More than one contaminated site exists within a typical operable unit. Multiple and sometimes conflicting requirements affecting point of compliance might therefore require resolution. Integration of these requirements with consideration of ultimate land use may become appropriate.

Adequacy of Existing Data/Data Quality Objectives - The Hanford Site has maintained a program of environmental data acquisition and analys is throughout most of its history. Because of continued progress in analytical methodologies and QA procedures, not all of these data would meet contemporary requirements for QC and QA. These historic data do, however, present a useful database on which to plan and possibly make ERA and IRM decisions. Use of these data are essential to the effective use of time and budget resources. Where necessary to support decisions, confirmatory or supplementary field sampling and other methods could be implemented, in an LFI for example, such that the body of data adequately met the DQO of the specific decision to be made.

DQO involving data used in decisions associated with investigation activities, abatement activities, and proof of remediation must be determined. Existing objective standards control whether data are valid. Guidance documents to be used in determining DQO include: "A Compendium of Superfund Field Operations Methods, "EPA, OSWER Directive 9355.0-14, Section 2.6.3 (intended data usage); "Data Quality Objectives," EPA OSWER Directive 9355.0-7B, Section 3.2, (proper consideration of data); and, Ecology's "Quality Assurance Management Plan." A strategy for meeting DQO for new data collected in pastpractice investigations at Hanford is proposed in this document. The concept of using a less qualified data set that is confirmed by fully qualified subset of data has been proposed in the document, "A Proposed Data Quality Strategy For Hanford Site Characterization." The concepts may be applicable to historical data sets. The use of these data would be based on the data meeting specific DQO for the analyses, decision or action at hand, and the inherent risk of proceeding with the activity. This would be decided by the unit managers of the operable unit llead regulatory agency approval in consultation with the support regulatory agency and DOE). In some cases, the action might proceed on the basis of the historical data alone, and, in other cases, the historical data would need to be confirmed by limited, validated new data, depending on the defined $D Q O$ and the risk involved in proceeding.

It might be appropriate to initiate an ERA or an IRM based on historical data that have not been collected with the benefit of contemporary QA standards. Sufficient confidence in the data could be attained through the evaluation and review of the data. During the 
abatement process, fully verified data meeting contemporary QA standards for decision making would be collected. The decision to issue a final ROD because of successful abatement activities, where the initiation of the abatement process was based on historical data, would be supported by data meeting the full applicable quality standards.

Another important aspect of the new strategy is the use of field screening techniques as a means of obtaining timely information for making interim decisions. Field screening techniques typically employ portable instrumentation or use mobile laboratories to perform analyses on a fast turnaround basis. It is recognized that the quality of such data may not be as high as fully qualified laboratory data and, thus, is usually not sufficient for final decision making on a site. However, such data are usually adequate for interim decisions or for planning further investigations. This is especially true if field screening confirms that contamination is present above action levels. The other benefit of field screening is that it gives the investigator more knowledge regarding the location of contamination so that samples taken for fully qualified confirmatory analyses can be selectively collected, thus reducing the total quantity of more expensive analyses.

It is also important that sampling and analysis plans be dynamic in considering prior results so that future sampling rounds might be more focused. EPA's guidance ${ }^{3}$ articulates this point as follows:

"A review of FS reports from completed projects often shows that even though round one sampling results are negative, the same parameter analyses are requested in each successive round. CLP resources are too valuable to be wasted. Scale back testing requirements by eliminating parameters that were conclusively negative in earlier tests."

Finally, and perhaps the most important element of the strategy regarding collection and use of data is the concept of concurrent characterization. This concept recognizes that as site cleanup proceeds through either an ERA or an IRM, characterization data would be obtained concurrently. The concept could also be termed "learn-as-we-go" and is the essence of the observation approach (Ref 2). The approach can be even more valuable in final remedy decision making because, in many cases, it can empirically assess remedial effects on a dynamic basis. For example, if a pump and treat system were operated as an IRM, mass removal and contaminant reduction can be directly measured against time. Without such data, design of a permanent remedy using the same technique would always be subject to considerable speculation, no matter how much modeling was performed.

Approval Mechanisms for Short-Term Actions and New Data - Mechanisms for regulatory approval of ERA and IRM must be established to assure that the most effective (environmental and cost) actions are taken. This mechanism would be equivalent to that described in Section 7.2.4 of the Tri-Party Agreement Action Plan. It is a recognized goal to only perform remedial activities at a site once. However, it is also acknowledged that, by their nature, ERA and IRM may not constitute the entire remedy for an operable unit. It is essential that the regulatory 


$$
\text { DOE/RL-91-40, Rev. } 0
$$

agencies be fully informed and have approval rights to applicable proposed cleanup actions, in accordance with Tri-Party Agreement Action Plan, Sections 7.2.3 and 7.2.4.

It is possible that data developed during the site characterization would indicate that sites thought to be contaminated turn out to be clean. These data would then suggest that further investigations of the sites be deferred until such time that cumulative risk assessments were completed for aggregate areas.

Cleanup Criteria - Criteria that would be used to $\mathrm{pl}$ an and implement cleanup should be developed in conjunction with the first FS or CMS to be conducted. Development of alternative methods for remedial actions would be keyed on the cleanup levels to which a site must be restored. These criteria must be developed early in the strategy, since they could in part depend on and influence decisions on land use. Guiding regulations to establishment of cleanup criteria are provided in 40 CFR 300 , 40 CFR 264, WAC 173-303, and WAC 173-340. Cleanup levels for final remedial actions would be based on ARAR and/or quantitative risk as sessment.

Use of Analogous Data from Similar Disposal Practices and Geology Within and among many of the operable units, there are areas that are geologically similar and that have experienced similar disposal activities. Significant savings in time, manpower, and budget could be realized by using these analogous conditions and activities to reduce the amount of investigation required at the affected sites. However, adequate confirmatory investigations would be performed in 1 ieu of full characterization efforts. It may be beneficial to define an aggregate area for such similar sites or areas as a composite of the specific units which are similar. Doing this would allow investigations and studies to be conducted for the group as a whole rather than individually for each similar unit, thus avoiding significant duplication of effort. This strategy proposes that the parties be afforted the flexibility to define such aggregate areas upon mutual agreement.

\section{CHANGES TO AGREEMENT PRIORITIES AND MILESTONES}

This strategy was developed with the intention of complying with the Tri-Party Agreement, as written. However, significant revisions to the associated Tri-Party Agreement Action Plan are required to implement the strategy. The parties have met to discuss specific changes to the Action Plan for the purpose of implementing this strategy. While final agreement has not yet been reached on the changes, proposed changes and justifications have been drafted and documented in Tri-Party Agreement Past-Practice Change Package, dated May 16, 1991. The parties are committed to reaching agreement on the change package at the earliest possible date.

Some of the key elements of the current draft change package are briefly described as follows:

- Proceed with work as-approved in the four approved work plans (1100-EM-1, 200-BP-1, 300-FF-1, and 300-FF-5) 
DOE/Fi-91-40, Rev. 0

- Defer preparation of certain new work plans until CY 1993

- Rescoping of 100 Area work plans that have already been drafted but are not yet approved; the rescoping would incorporate this strategy.

- Construction of a site-wide, or at least an area-wide groundwater model

- Development and documentation of site-wide risk assessment methodology

- Conducting a focused study to determine the effect of the Columbia River on the hydrology and contaminant migration within the 100 Area operable units

- Conducting a cumulative risk assessment for the 100 Area

- Conducting three 100 Area feasibility studies

- Redefining 200 Area source term operable units into waste area groups and then completing an AAMS for each waste area group

- Defining two aggregate areas for 200 Area groundwater plumes and completing AAMS for each area.

This change package is consistent with the consensus/decision process established for the Tri-Party Agreement signatory parties to change the priorities and associated milestones. This process is documented in the TriParty Agreement Action Plan, Section 12.0. Any proposed changes to Tri-Party Agreement priorities or milestones would be consistent with the goal of all the parties to expeditiously approach the reduction of risk to human health and welfare and the environment as a result of Hanford operations.

\section{NATIONAL ENVIRONMENTAL POLICY ACT (NEPA) COMPLIANCE}

DOE has made a policy decision that it must comply with the documentation requirements of NEPA at the operable unit level. EPA, Region 10, does not concur with DOE that NEPA applies at the operable unit level for investigations and remedial actions which occur under CERCLA authority at a federal facility NPL site. Ecology is in agreement with EPA on this matter and maintains a similar position for Ecology past-practice lead sites.

Resolution of the issue of NEPA applicability to CERCLA and RCRA pastpractice cleanup activities and the proper level it should be applied (waste site, operable unit, NPL site, Hanford Site, etc.) is being actively pursued. The issue is being discussed through the highest levels at DOE, EPA, Ecology, U.S. Department of Justice, and the Council on Environmental Quality.

When the final resolution is completed, it will be incorporated into this strategy. In the interim, the existing language of Section 5.7 of the Tri-Party Agreement Action Plan will apply. 
DOE/RL-91-40, Rev. 0

\section{STRATEGY}

A major aspect of this strategy is the initial evaluation of existing data on an aggregate area basis. The approach requires the definition and approval of such aggregate areas where they are not defined in the Tri-Party Agreement. Existing aggregate areas might need to be redefined to accomplish the goals of this strategy. These aggregate areas would provide the basis for detailed assessment of all operable units contained within the aggregate area prior to the development of the Hanford past-practice work plans.

The use of existing data meeting DQO and confirmed with new data, where necessary, is a pivotal element in the objective of gaining efficiencies and the ultimate success of the Hanford past-practice strategy. Combining more effective use of existing data with better management of uncertainty in the decision process would allow a reduction in the number of sampling episodes. This would also help expedite treatability studies, FS, and cleanup actions, including ERA and IRM.

Defining the acceptable levels of uncertainty in the data and data analyses for each decision is the initial step in the streamlining process. RI tend to stretch out because inherent data uncertainty makes the highly subjective decision of when to stop sampling very difficult and hard to defend. Concepts proposed in EPA's MSR (Ref 1) and Observational Approach (Ref 2) are incorporated into the Hanford past-practice strategy to help address this issue. The MSR proposes to limit field sampling episodes by defining objectives and acceptable uncertainty through structured planning and quantificaition, as much as possible. The observational approach proposes to address uncertainty of data and data analyses in the decision process by defining the expected (probable) conditions and reasonable deviations to those conditions with contingencies provided in the ultimate decision.

Three basic tenets of the observational approach are: (1) characterization should be undertaken for a specific purpose, such as the selection of a remedy or identification of sites needing ERA or IRM, not just to study contamination or site characteristics; (2) more data do not necessarily lead to less uncertainty; and (3) convergence on a response action as early as possible is the goal. Acceptance of uncertainty within reasonable constraints and reasonable contingency planning are synergistic in this approach.

The EPA MSR (Ref 1 ) identifies a process to expedite the feasibility and treatability study processes. These concepts are incorporated into the Hanford past-practice strategy. FS or CMS are proposed to be initiated in the scoping stage. Such studies would limit the number of alternative technologies evaluated to only those which address likely contaminants and environmental conditions. Consistent with the stated goals of the NCP, treatment alternatives would always be considered, focusing on technologies that offer the potential for comparable or superior performance as proven technologies. If new contaminants or site conditions are found, there is opportunity to adjust plans. In this way, evaluation of remedial alternatives becomes a process of starting with what is likely to work to the extent that existing information supports the desired level of certainty and making adjustments if significantly different contaminants/conditions are found. The existing method is to try to screen out a large array of alternatives and justify why the nonselected alternatives are not likely to work. Early 
consideration of probable remedial technologies allows data collection of those specific data needed to evaluate and implement those limited technologies, thus limiting multiple field sampling episodes. The MSR also proposes to conduct treatability studies during the RI. The effectiveness of the selected treatment technology is therefore known with increased certainty at the ROD. Since treatability testing is costly and time consuming, a limited number of promising technologies would be tested As part of the Hanford past-practice strategy, generic treatability studies should be initiated early in the overall Hanford cleanup schedule.

Opportunity for public involvement in the decision process is mandatory and beneficial. If the data support ERA or IRM conducted prior to issuing the ROD or permit modification, public notice and opportunity to provide comment to that decision is afforded in Section 10.5 of the Action Plan of the TriParty Agreement.

Figure 1 is a decision flow chart of the Hanford past-practice strategy. The process begins with evaluation of existing data, which then triggers decisions leading the process along any one or more concurrent paths.

\section{DATA EVALUATION}

The 20 initial operable units of the Tri-Party Agreement Action Plan were prioritized based on an initial assessment of risk potential to ensure that action is focused on the greater hazards. The decision criteria are presented in Section 3.4 of the Tri-Party Agreement Action Plan and the results of the prioritization decisions are listed in Appendix $C$ of the same plan. The parties have agreed that some redefinition of operable unit boundaries and site priorities is necessary to fully use the aggregate area approach, which is the cornerstone of this strategy. This redefinition has had to consider the status of work plan preparation and approval, i.e., the fact that some work plans have already been approved and many of the 100 Area work plans have already been drafted but not yet approved. In addition, consideration has been given to inherent differences between the 100 and 200 Areas in the Action Plan definition of operable units. For example, separate groundwater operable units have been defined in the 100 Areas, but not in the 200 Areas.

The draft Tri-Party Agreement Change Package recognizes three distinct approaches that are tailored to fit the differences in work plan status and/or operable unit configuration:

1. Approved Work PIan Sites - RI/FS work for operable units that have approved work plans (1100-EM-1, 300-FF-1, 300-FF-5 and 200-BP-1) will be completed in accordance with the currently approved work plans with additional interim milestones added to assure timely completion of the RI/FS work.

2. 100 Areas - Work plans already drafted for the 100 Areas will be rescoped with the rescoping aimed at placing the initial focus of the intrusive investigations on the highest priority waste sites within each operable unit for which a work plan has been prepared. Priority sites will be determined by negotiation among the parties. Aggregate areas will be defined in the future based on 
the unit of aggregation that optimizes the efficiency of the investigation. For example, it may be that an earlier record of decision can be reached for higher priority, similar waste sites contained in different operable units. However, for purposes of cumulative risk assessment, it may be most efficient to define the entire 100 Area NPL as the aggregate area. Thus, the strategy allows the parties the flexibility to define the most efficient investigation or study basis from which to make decisions.

3. 200 Areas - The 200 Area approach is somewhat different than the 100 Area approach in that eight waste area groups representing major source terms generally associated with operating plants are defined for aggregate area management studies (AAMS). In addition, two aggregate groundwater areas are defined, one for 200 East Area and one for 200 West Area. These 10 aggregate areas will form the basis for the initial 200 Area AAMS.

The parties have the flexibility to define aggregate areas appropriate to achieve investigation and cleanup objectives. Regardless of how they are defined, the data evaluation task for the AAMS would have the same objectives in all cases. That is, the existing body of information regarding past characterizations of sites within the aggregate area would be searched, compiled, analyzed, and interpreted such that informed decisions might be made as to which path(s) to pursue for further actions in the defined aggregate area. Such decisions might also include redefinition of aggregate areas for further studies or actions if the data show that changes are justified. Decisions of this type would be made by mutual agreement of the parties, subject to the change process in the Tri-Party Agreement Action Plan, Section 12.

For the 200 Areas, the data evaluation task follows the aggregate area management study (AAMS). The AAMS is similar in nature to a scoping study. Scoping studies are considered in Section $300.430(\mathrm{~b})$ of the NCP and proposed 40 CFR 264.511. Both regulations are designed for characterizing and addressing hazardous substances at sites with considerable less complexity and data than Hanford.

The intent of the AAMS is to:

- Assemble and evaluate existing data (establish associated DQO)

- Identify the need for ERA and IRM (see ERA and IRM paths below)

- Identify likely contaminants and response scenarios and potentially applicable technologies

- Focus required new work (based on DQO) under the work plan (e.g., for the rescoping of the existing 100 Area work plans)

- Provide for the opportunity to perform limited new site characterization work if data or interpretation uncertainty could be reduced by the studies (see LFI path below). This is similar in concept to preliminary assessment/site investigation (PA/SI) studies or RCRA facility assessment (RFA) process 
- Build defensible conceptual models for further site characterization, the development of performance assessment models and proposed remedial/corrective actions; and report the data and analyses described above (see IRM path).

The regulators would be involved throughout the AAMS process. Periodic meetings (e.g., monthly) would be utilized to transfer information and to provide progress status. The time required to perform an AAMS and produce the aggregate area management study report (AAMSR) is specified in Milestone M-27 of the Tri-Party Agreement Action Plan.

The AAMSR would be a secondary document and would present the knowledge gained from the AAMS. The document, its content, and format would be decided during the data-gathering phase, and would be dependant on the data and possible analyses and decisions that could be supported. However, depending on the quantity of available information, the data would probably be presented in separate topical reports. The intent of the AAMSR is to expedite the process by relying on existing data, as much as possible, with confirmatory studies, and to focus investigations as much as possible.

Included in the AAMSR would be:

- Description of the site and the proposed conceptual model

- Data, data evaluatiors and data quality

- Interpretation of the accumulated data

- Identification of areas within the operable units where sufficient data exist to support future ERA, IRM, and risk assessments

- Assessment of the aggregate area and the need for refinement of operable unit boundaries, providing for operabie units where records of decision could be achieved and decisions concerning cleanup could be made early in the process

- Prioritization of the included operable units or waste sites within the operable units

- Additional data and analyses that are needed

- Assessment of potential remedial technologies.

Information obtained and analyzed in the AAMS would be used as a basis for decision making along the paths described in this strategy, i.e., ERA, IRM, LFI, and final remedy selection for the operable unit. For example, if the AAMS has provided sufficient information to formulate a conceptual model and qualitative risk assessment and an IRM is not justified, then further investigations would be deferred to final remedy selection. In this phase, these contamination levels would be evaluated to determine if cumulatively for an operable unit or aggregate area risk exceeds acceptable limits.

The AAMS includes an efficient consideration of remedial technologies by limiting the numbers of alternatives considered. Existing site and contaminant knowledge is used to realistically limit the alternatives as early as 
possible. This concept has been proposed for the scoping phase of superfund sites by the EPA (Ref 1 ). In addition, early consideration of remedial technolcyies allows for efficient data collection during LFI or during the early RI (RFI) phase for those special data needed for an FS (CMS).

For the 100 Areas, the data evaluation task would constitute the rescoping of the existing operable unit work plan drafts and the scoping of work for operable units not yet covered by work plans. The rescoping will be aimed at $p$ ?acing the initial focus of the intrusive investigations on the highest priority waste sites within each operable unit with a goal of evaiuating the need for interim remedial measures. The collective knowledge of the three parties and the information contained in the existing work plans would be sufficient to identify the high priority waste sites. Focusing on the high priority sites would result in data on the more critical sites at an earlier point in time to allow earlier ROD for the higher priority sites or for an entire operable unit. This concept of a focused ROD could apply to similar waste sites contained in different operable units. This approach has an additional advantage of reducing the amcunt of work required to prepare future work plans for operable units not yet scoped. Revised interim milestones are proposed in the draft TPA change package for rescoping of existirig work plans and for suhmittal of new 100 Area plans.

\section{EXPEDITED RESPONSE ACTION PATH}

Throughout the period from the initiation of the data evaluation process to the final site ROD ur permit modification, a question would be continually assessed: "Is an ERA justified?" Criteria for addressing this question are listed above in the section entitled "Expedited Response Action Decision. "If the answer to tris question is yes, action would proceed consistent with the requirenants set forth in 40 CFR 300.415 and/or proposed 40 CFR 264.540.

A11 decisions regarding [RA would be documented in a Tri-Party Agreement Action Memorandum. made in accordance with the Tri-Party Agreement Action Plan. Section 7.2.4. Guidance for preparation of action memoranda is available in OSWER Directive 9360.0-03B.

An assessment would be made of the ERA performance when possible. This assessment would evaluate whether site-wide priorities justified continuing remedial investigations at the site(s) in the near term. If there was such justification, the process would proceed to the IRM path to evaluate whether data were sufficient to formulate a conceptual model and qualitative risk assessment (see IRM Path). If there were not a priority justification, then further investigations would be deferred to the final remedy selection phase. For decisions in this path, DOE would function as the lead agency. However, decisions would be made upon discussion and negotiation by all the parties with the final decision residing with the lead regulatory agency in accordance with the Tri-Party Agreement.

Funding for ERA will be accomplished by carrying a cost account plan (CAP) in the DOE-RL Environmental Restoration budget specifically for that purpose. The funding level will be negotiated, and will reflect the iverall priorities of performing ERA in relation to other environmental restoration planned work. Both non-time-critical and time-critical ERA will be funded from this account. A second funding option available is to consider an ERA as 
"additional work" under paragraphs $90-92$ of the Tri-Party Agreement. If this second option is utilized, the Tri-Party Agreement Action Plan milestone(s) would be changed to reflect the decisions.

Time-Critical ERA Decision - Actions would proceed in response to this decision when the data indicate that near-term action is necessary to abate a threat to human health or welfare or the environment. Actions in this category are responsive to time-critical situations, such as emergencies or other situations where the abatement action must be initiated within 6 months to abate the threat. It is expected that this situation would occur only very rarely. However, because the situation might be encountered, the process for addressing it must still be considered.

If a threat to human health or welfare or the environment is found to exist and the decision is made to perform an ERA, the action would not necessarily preclude continuation of the processes defined by the parallel paths (IRM, LFI, RI/FS). The AAMS or data evaluation tasks would proceed in tandem with the abatement process as well, within resource and budget constraints.

The ERA would be consistent with either CERCLA or RCRA requirements and would be documented in a Tri-Party Agreement Action Memorandum. Public involvement with regard to the memorandum would proceed in accordance with the NCP requirements of 40 CFR $300.415(\mathrm{~m})(1)$ through (3). Under the NCP, in emergency and other time-critical situations, the removal action can be initiated without prior public involvement. However, public notification of the availability of the administrative record file is required within 60 days of initiation of onsite activity. A 30-day public comment period begins at the time the file is made available to the public (40 CFR $300.820(\mathrm{~b})(2))$. Following the public comment period, the lead agency must then provide written response to significant comments. Additional requirements are specified in the NCP regulations (40 CFR $300.415(\mathrm{~m})(3)$ ) for actions that are expected to extend beyond 120 days from the initiation of onsite activities. For interim measures conducted under RCRA authority, public notification and comment requirements are less straightforward. Proposed 40 CFR 264.540 refers to the procedures of proposed 40 CFR 270.34 and 270.41 when the Regional Administrator determines that a modification to the permit schedule of compliance is necessary to implement an interim measure. Additional notification requirements are specified in responses to imminent hazards under RCRA Section 7003 actions. To provide for a uniform and integrated process for handling public involvement in time-critical ERA, this strategy proposes to utilize the NCP requirements of 40 CFR $300.415(\mathrm{~m}) 2$ ) for all timecritical ERA including RCRA interim measures, using the Tri-Party Agreement Action Memorandum as the vehicle to initiate the public involvement process. Following the public comment period, the ERA would be completed.

Non-Time-Critical ERA Decision - The data would be assessed and judgement would be applied to evaluate the potential threat to human health and welfare and the environment. Consideration would be given to the criteria listed above in the section entitled "Expedited Response Action Decision." As such, and similar to a time-critical ERA, these 
decisions potentially impact other Tri-Party Agreement compliance work. Ecology and EPA maintain authority to mandate ERA within the authorities specified in RCRA, CERCLA and the Agreement; however, every effort should be made so that the decision is not unilateral. All parties agree to consultation on the proposed action. The proposed action would be documented in a Tri-Party Agreement Action Memorandum. Impacts on the overall program would be considered in the decision.

A non-time-critical ERA could cover a wide range of actions. Examples would include a relatively simple removal of surface contamination or removal of buried drums. In general, however, ERA would be more appropriate for relatively straightforward, low complexity responses that could be implemented in a relatively short time-frame, e.g., weeks or months as opposed to years. Cases involving relatively complex and more significant actions such as "pump-and-treat" groundwater cleanup efforts, in situ stabilization of waste sources, or managing groundwater injection and withdrawal to stabilize contaminant plumes might be more appropriate for the IRM path.

The decision to conduct the action under removal authority as an ERA or under remedial authority as an IRM would use criteria defined in the NCP preamble (55 FR 8704) as follows:

1. The criteria listed in the objectives section of this strategy and requirements in the NCP for taking removal actions

2. The availability of resources

3. The urgency of the site problem.

Under CERCLA, removals are distinct from remedial actions in that they may abate or stabilize the threat rather than comprehensively address all threats at a site (55 FR 8695). While not being required to attain all ARAR, removal actions are expected to attain ARAR "to the extent practicable." (40 CFR 300.415(i)). Remedial actions, in contrast must comply with all ARAR (or invoke a waiver). Removal authority is mainly used to respond to situations where long deliberation prior to response is not feasible. Planning time and the near-term, focused purpose of removal actions may combine to circumscribe the practicability of compliance with ARAR during individual removal actions. It is recognized in this strategy, however, that there are also some non-timecritical situations that are appropriate for removal actions. Consistent with the requirements of 40 CFR $300.415(b)(4)$, whenever a planning period of at least 6 months exists before onsite activities must be initiated, and the lead regulatory agency determines, based on a site evaluation, that a removal action is appropriate, the lead agency will conduct an engineering evaluation/cost analysis (EE/CA) or its equivalent. The EE/CA documentation would be subject to public comment in accordance with 40 CFR $300.415(\mathrm{~m})(4)$.

Interim measures conducted as ERA under RCRA authority would proceed in a similar manner to CERCLA removal actions except that the regulatory framework for actions would follow the 40 CFR 264.540 requirements, when promulgated. While the proposed regulations for RCRA 
interim measures do not require an equivalent of the CERCLA EE/CA, an interim measure proposal would be documented in a Tri-Party Agreement Action Memorandum. A permit modification might also be required as described in proposed 40 CFR 270.34 and 270.41. Specific documentation requirements would be determined by the lead regulatory agency commensurate with the specific action(s) to be taken. Guidance is pro:ided by EPA in OSWER Directive 9902.4, "RCRA Corrective Action Interim Measures," June 10, 1987. This directive describes the preparation of an "interim measures work plan." An interim measures work plan is analogous to an $E E / C A$.

\section{INTERIM REMEDIAL MEASURES PATH}

The IRM path would first decide whether data are sufficient to formulate a conceptual model of the site and perform a qualitative risk assessment. If data are sufficient, then threshold contamination levels and the conceptual model would be defined, the qualitative risk assessment would be performed and remedial alternatives would be identified and screened. Types of uncertainty in the data key to the decisions and the consequences of making the decisions will be evaluated. If the contamination levels exceed threshold values, an IRM remedy would be selected, after performing a focused feasibility study, if necessary. The proposed plan would then be written, issued for public

comment, and the IRM implemented. During the IRM, concurrent characterization would be performed to continue gathering data regarding site contamination. After completion of the IRM, the data which include those obtained in concurrent characterization, would be evaluated to determine if a final ROD could be issued for the site. If sufficient data existed to select a final remedy, then the ROD would be issued following preparation of the proposed plan and public comment period. If sufficient data did not exist, then the LFI path would be explored to assess whether additional data could be obtained in an LFI or whether a more extensive RI/FS would be required.

If the conceptual model showed that contamination did not exceed threshold values, then the investigation would be deferred to the aggregate area cumulative risk assessment phase. The deferral decision would be subjected to public comment.

Interim remedial measures that are determined by the regulatory agencies to be appropriate for implementation as IRM under remedial authority would be subject to requirements of 40 CFR 300.430. Similar to what is described in 55 FR 8703 - 8706 to implement an interim action under remedial authority, an operable unit or aggregate area for which an interim action is appropriate would be identified. Data sufficient to support the IRM decision would be extracted from the AAMSR or other data sources. Few alternatives, and in some cases perhaps only one, should be developed for IRM. A completed baseline risk assessment generally will not be available or necessary to justify an IRM. Qualitative risk information should be organized that demonstrates that the action is necessary to stabilize the site, prevent further degradation, or achieve significant risk reduction quickly. Supporting data, including risk information, and the alternatives analysis could be documented in a focused FS report. However, in cases where the relevant data could be summarized briefly and the alternatives were few and straightforward, it might be adequate and more appropriate to document this supporting information in the proposed plan that is issued for public comment. This information should also be summarized 
DOE/RL-91-40, Rev. 0

in the ROD. While the documentation of IRM decisions might be more streamlined than for final actions, all public, state, and natural resource trustee participation procedures specified in the NCP would be followed for such actions as well as procedures specific to the Tri-Party Agreement.

\section{LIMITED FIELD INVESTIGATION PATH}

This path would be followed if in the IRM decision the determination is made that data were not sufficient to formulate a conceptual model of the site(s) and to perform a qualitative risk assessment. The LFI path then starts by identifying the minimum additional data requirements for an IRM decision. If such data needs could be satisfied by an LFI, then the investigative work would be scoped as a statement of work, which would include a schedule of implementation. This statement of work would then be discussed and negotiated with the regulatory agencies. Upon agreement by the parties, the scope would then be implemented by performing the limited field investigations. The LFI would also include studies to identify and screen remedial technologies. The LFI results would then return to the data evaluation phase, to revisit decisions regarding performing ERA or IRM.

\section{FINAL REMEDY SELECTION}

An overall objective of this strategy is to maximize the options available to perform interim cleanup actions where contamination levels pose unacceptable human health and environmental risk (site characterization is performed concurrently with the cleanup actions). In this way, federal funds and resources are directly applied to beneficial uses in a more efficient manner; less time and resources are spent on pre-ROD site characterization, more time and resources are spent on cleanup. However, not all of the necessary data needed to complete the RI/FS (RFI/CMS) process can be obtained through interim cleanup actions. There is a need to maintain some level of effort for long-term data collection needs to address final remedy selection on the operable unit/aggregate area/NPL site scale and address those sites not chosen for interim cleanup actions. An example of this concern is the cumulative risk posed from the known 373 waste sites in the 100 Area to salmon spawning beds in the Hanford Reach. Therefore, the "Final Remedy Selection", shown on Figure 1 , is intended to (1) evaluate what long-term studies are needed to address human health and environmental risk early in the process, and provide for those data as required to meet the Tri-Party Agreement final cleanup milestone; and, (2) accumulate and assess all of the data provided throughout the process with the goal of final remedy selection on the operable unit/aggregate area/NPL site scale. The Hanford RI/FS (RFI/ CMS) process culminates in summing the data collected in the operable unit.

The final remedy selection completes the RI/FS (RFI/CMS) process. This is accomplished by accumulating the data provided by the AAMSR, the cleanup actions from the ERA, IRM, and LFI paths, and the data provided by those studies initiated under the "Final Remedy Selection" as described above. Every effort is expected to be used to streamline the process, while maintaining defensible decisions. 
Under the Hanford past-practice strategy, operable units would have work plans prepared, reviewed, and approved as primary documents. The work plans would describe in detail (as used in this paragraph includes "by reference if available") what is known about the site; describe in detail the agreed-upon focused investigations under the LFI and final remedy selection; describe in detail agreed-upon ERA and IRM actions; and, describe in general terms the overall RI/FS (RFI/CMS) process and schedule to reach the final ROD. As these activities progress and the RI/FS (RFI/CMS) process evolves, the subsequent new work and necessary changes to the described activities in the work plan will be documented in work plan addendums, scope of work statements, and operable unit meeting minutes. Thus, the work may proceed in phases that allow for incorporation of "lessons learned". Documentation of the process is a continuum, thus streamlining the process.

Groundwater, surface water, and stream sediment investigations would be performed under a groundwater aggregate area work plan. A parallel effort covering vadose zone investigations, air, and terrestrial biota would be included in the priority (most significant contributor) source operable unit work plan. The groundwater aggregate area work plan would provide for a "screening" investigation of potentially significant source term areas outside the priority source operable unit. This approach would be taken when there is a high probability that such source terms are contributing or might significantly contribute to near-term groundwater contamination. Reprioritization of operable unit rankings might result from this process.

Using this approach, a redefinition of operable units might be necessary. Such redefinition would be considered when the aggregate area could be subdivided in a manner that would allow facilities with similar source terms and site conditions to be characterized and remediated in a similar manner.

A situation exists where widely separated operable units having equivalent operating histories and similar hydrogeologic regimes are to be addressed, e.g., in the 100 Areas. In such a situation, it would be appropriate to consider performing definitive investigations and remedial measures on selected waste sites. Subsequent investigations would then use the findings of the definitive studies and remedial actions to refine data needs for similar operable units. These subsequent studies would serve to verify findings and assumptions of the "primary" investigations as they apply to similar operable units, in addition to providing site-specific information necessary to support ROD or modification to the Hanford Site RCRA permit. Work plans/reports/ROD/permit modifications and associated review requirements would thus be reduced. The scope of work deemed necessary to achieve a ROD would be defined and scheduled. The work would be phased, to include logical evaluation steps where the data are evaluated and the remaining planned investigations and associated milestones are reassessed.

The concept of phasing RI/FS work is well established in EPA guidance (Ref 3):

"Phasing an investigation allows you flexibility in the early stages of the work by not requiring high levels of sampling accuracy or precision while establishing ball-park values. These phase one data then become design parameters for followon focused data quality objectives. 
To benefit from conducting the RI in "phases," each phase must be designed to use the information developed in prior work. This will improve the design of subsequent steps and improve efficiency. By phasing the work logically, you can identify potential mistakes or faulty initial information and save valuable time and expense by not developing unproductive lines of investigation. Logical phasing allows you to focus on a more narrowly defined objective."

To implement the RI/FS (RFI/CMS), the work would be performed as described in the approved work plan. Existing data would be confirmed, and data gaps would be filled by new data satisfying appropriate data quality objectives necessary to support a desired level of certainty in a decision. The groundwater flow affecting the site would be investigated and described in a conceptual flow model. Site, local, and regional data necessary to perform performance assessment models for risk analysis would be collected. The nature and extent of contamination would be determined (plumes in the groundwater system and distribution within the vadose zone for source units). Areas of probable contamination suspected by process and site knowledge would be investigated. Data identified as necessary for the baseline risk assessment would be collected, including any necessary confirmatory sampling. Data for feasibility studies and treatability studies would be collected and evaluated as soon as possible during the RI (RFI) investigation. If future remedial activities were necessary, these activities would continue and would develop based on new data gathered. It is the intent of this strategy to collect and to analyze sufficient data in this initial phase such that the requirements defined in the AAMS would be fulfilled. The probable trigger for additional work would be the identification of conditions not foreseen in the original work plan. An example would be if data showed that the conceptual model was no longer valid.

The EPA has also recognized efficiencies in expediting treatability studies when obvious technologies can be selected early in the process

(Ref 1). Once the need for treatability testing is identified in the AAMS, collection of samples needed for bench-scale treatability tests could be scheduled to occur early in the RI. Results could be available for use during detailed evaluation of remedial alternatives and would indicate whether a technology would or would not meet ARAR and other risk-based criteria. If not, there would be less time lost in the evaluation of other alternatives.

The RI/FS (RFI/CMS) report would describe the interpretation of data gathered in the RI/FS (RFI/CMS). It would include a detailed description of the site(s) and the distribution of wastes at those sites. Because of the probable large volume of data that would be collected, for the most part, data might be reported separately. Companion to the site and waste distribution descriptions would be the FS (CMS), which would describe evaluations of remedial alternatives. Previously existing data and new data generated in the RI (RFI) would be used as input to the FS (CMS). This report would be a primary document.

Once the RI/FS was completed, the data would be evaluated for a decision to go to the final ROD. This decision would be generally based on results of the FS or CMS. If there were insufficient data to support a ROD or permit modification, the process would return back to the data evaluation step to decide on justification for an ERA, IRM, LFI, and/or additional RI 


$$
\text { DOE/RL-91-40, Rev. } 0
$$

investigations. If data were sufficient to support the final ROD or permit modification, then the path would proceed to preparation of the proposed plan, public comment, and issuance of the final ROD or permit modification.

Additional RI investigation effort, if necessary, would be performed under an approved addendum to the original work plan. The objectives would be to fill the data gaps for site characterization, risk assessment, and treatability. Data would also be collected for the selection of alternative remedial or corrective actions.

\section{IMPLEMENTATION}

Implementation of this strategy will require close cooperation of all the parties. This strategy proposes that changes in the current way of doing business and alterations or reinterpretations of deliverables under the TriParty Agreement are probably needed. This strategy allows for rapid response in areas identified as requiring early remediation to limit environmental degradation. As such, the strategy achieves a crucial objective, that of proceeding with cleanup of the Hanford Site at the earliest possible time.

Agreement-in-principle with the strategy and intent to continue incorporation of the strategy into the Tri-Party Agreement will be accomplished through transmittal of agreement letters by the three parties.

\section{REFERENCES}

1. Johnson, Gary L. (U.S. EPA) and Lynda H. Wynn, (Research Triangle Institute), "A Management Systems Review of the Superfund RI/FS: Opportunities for Streamlining," Journal of the Air and Waste Management Association, May 1990.

2. Myers, R. Scott (Pacific Northwest Laboratory), "The Observational Approach for Site Remediation at Federal Facilities, " Proceedings of the Sixth Annual Waste Testing and Quality Assurance Symposium, July 1990.

3. U.S. Environmental Protection Agency, "Scoper's Notes, An RI/FS Costing Guide, Bringing in A Quality RI/FS On Time and Within Budget," EPA/540/G-90/002, February 1990 . 


\section{memorandum}

DATE: NOV 079991

REPLY TO ATTN OF:

EM-442 (M. Harmon, 353-8167)

SUESECT:

HANFORD SITE PAST PRACTICES INVESTIGATION STRATEGY, AUGUST 1991

TO:

Leo E. Little,

Assistant Manager, RL

We have reviewed the subject document and concur with the technical and programmatic strategy set forth in the document. We feel that the approach described in the strategy will enhance the cleanup process and result in substantial time and resource saving. With this concurrence, you are authorized to release this document to the State of Washington Department of Ecology and the United States Environmental Protection Agency.

If you have any questions or comments please contact me or Mary Harmon of my staff.

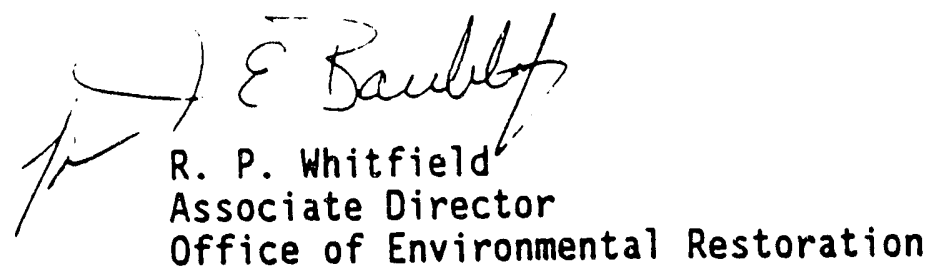

cc:

S. Mann, EM-44

E. A. Bracken, RL

RECEIVED 
DOE/RL-91-40, Rev. 0

Attachment 2

Page 1 of 2

STATE OF WASHINGTON

\section{DEPARTMENT OF ECOLOGY}

Mail Stop PV-11 • Olympia, Washington 98504-8711 • (206) $459-6000$

March 17, 1992

Steven H. Wisness

Hanford Project Manager

U.S. Department of Energy

P.O. Box 550, A5.19

Richland, WA 99352

Re: Hanford Past Practice Investigation Strategy Document

Dear Mr. Wisness:

The Environmental Protection Agency (EPA) and Washington State Department of Ecology (Ecology) have completed the review of the most recent version of the Hanford Past Practice Investigation Strategy Document, dated March 1992. We would like to applaud the efforts of all the people who have worked on this strategy over the past two years. Special thanks should go to Michael Thompson, of your staff, as the primary author. The goal of streamlining past practice investigations at Hanford is shared by EPA and Ecology; we view the strategy as the parties' best collective effort to date to achieve a more efficient and action oriented process. We should continue to evaluate the process and make further improvements as we gain more experience.

EPA and Ecology agree that the subject strategy document is acceptable for use in the Hanford past practice cleanup program. We expect that implementation of the strategy may result in some initial confusion as various individuals interpret the requirements. Therefore, we will be providing close oversight during implementation to ensure consistent application and interpretation. If significant problems are encountered or foreseen, we will endeavor to bring them to your attention immediately. We would ask that you also provide a close review of the process during the early stages of implementation and work with us to quickly resolve issues.

The next step to finalize the strategy is to modify the Hanford Federal Facility Agreement and Consent Order (Tri-Party Agreement) Action Plan, Section 7.0 to reflect the new approach. This can be accomplished as part of the next amendment to the Tri-Party Agreement.

RECEIVED

IIAR 201992

DOE-RLCCC 
Steven H. Wisness

March 17, 1992

Page 2

Again, we appreciate your efforts in development of this strategy. If you have any questions or concerns, please contact Paul Day at

(206) 376-6623, or Dave Jansen at (206) 438-7021.
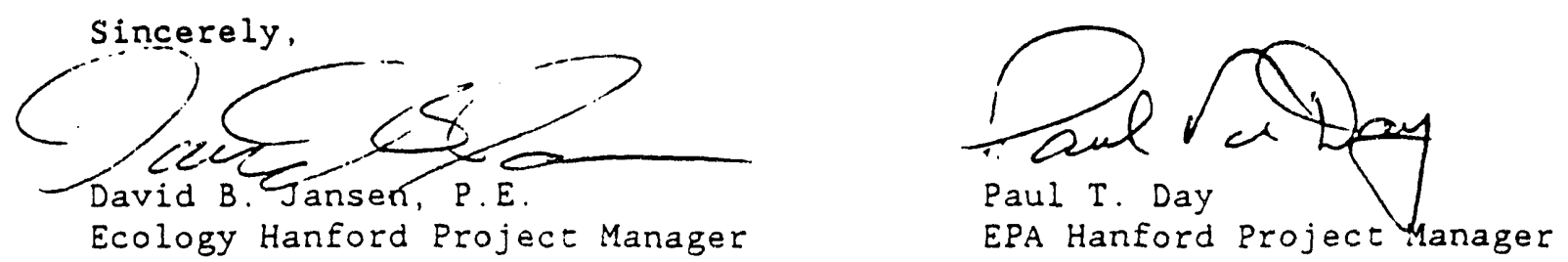

$D J: L G: j w$

cc: Julie Erickson, DOE

Larry Goldstein, Ecology

Mike Thompson, DOE

Iim Veneziano, WHC 
DOE/RL-91-40, Rev. 0

\section{DISTRIBUTION}

\section{Number of Copies}

Onsite

46

U.S. Department of Energy, Richland Field Office

J. K. Erickson (30)

A5-19

K. M. Thompson (15)

Public Reading Room

A5-15

Al -65

1

Pacific Northwest Laboratory

Hanford Technical Library

P8-55

18

Westinghouse Hanford Company

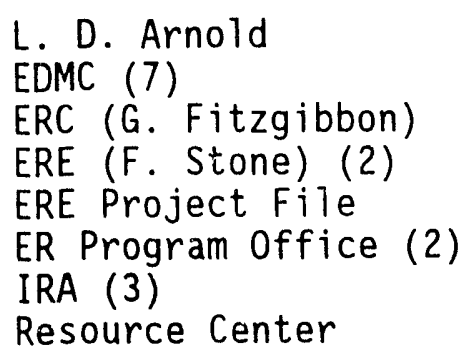

L. D. Arnold

EDMC (7)

ERC (G. Fitzgibbon)

ERE ( $F$. Stone) (2)

ERE Project File

ER Program Office (2)

IRA (3)

Resource Center

B2-35

H6- 08

H6-07

H6-01

H6-03

H6-27

$\mathrm{H} 4-17$

N3-05 

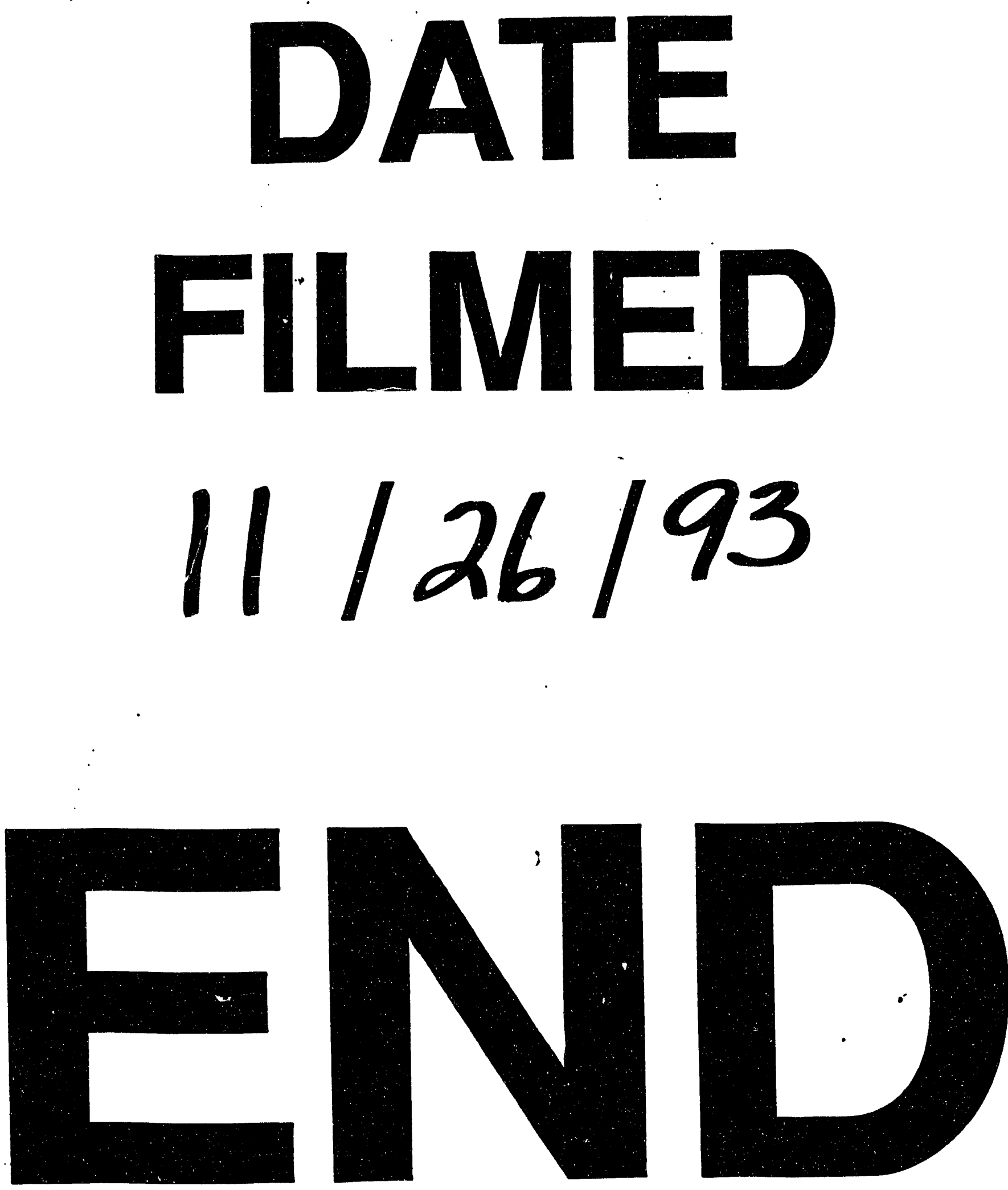
